\title{
Soluble Interleukin-2 Receptor Level at Diagnosis Predicts Prognosis of Patients With Follicular Lymphoma Irrespective of Initial Management Strategy
}

\author{
MASAHIDE YAMAMOTO ${ }^{1}$, KEISUKE TANAKA ${ }^{2}$, YOSHIHIRO UMEZAWA ${ }^{1}$, \\ TOSHIKAGE NAGAO $^{1}$, SHIGEO TOYOTA ${ }^{2}$ and OSAMU MIURA ${ }^{1}$ \\ ${ }^{1}$ Department of Hematology, Tokyo Medical and Dental University, Tokyo, Japan; \\ ${ }^{2}$ Department of Hematology, Yokosuka Kyosai Hospital, Kanagawa, Japan
}

\begin{abstract}
Background/Aim: Although various prognostic indices for follicular lymphoma (FL) have been proposed, they are designed specifically for patients requiring immediate therapy. We aimed to develop a new simple prognostic tool applicable for all patients with FL at diagnosis. Materials and Methods: We retrospectively analyzed various clinical, pathological, and laboratory data, including soluble interleukin-2 receptor (sIL2R), from 140 patients with FL from two centers for their impact on prognosis. This study analyzed the impact of soluble interleukin-2 receptor (sIL2R) in order to develop a new simple prognostic tool applicable for all patients with FL at diagnosis. Results: The initial management of these patients was watchful waiting $(n=48)$ or immediate treatment $(n=92)$. Event-free survival at 24 months predicted overall survival. When categorized into three groups according to the sIL $2 R$ levels at diagnosis, a very high sIL $2 R$ level identified about $20 \%$ of patients with a distinctively worse survival compared to the others. Conclusion: sIL2R is a very effective biomarker that can be easily applied in routine practice to predict survival for all patients with FL at diagnosis irrespective of initial management approach.
\end{abstract}

Follicular lymphoma (FL) accounts for about $20 \%$ of all lymphoma cases and is the most common subtype of indolent B-cell lymphoma $(1,2)$. Prognosis of FL has improved, with median overall survival reported to be over 18 years (3). However, because the survival curve dose not reach a plateau, FL is still considered incurable. Thus, for

Correspondence to: Masahide Yamamoto, Department of Hematology, Tokyo Medical and Dental University, 1-5-45 Yushima, Bunkyo-Ku, Tokyo 113-8519 Japan. Tel: +81 358035211, Fax: +81 358030131, e-mail: hide.hema@tmd.ac.jp

Key Words: Soluble interleukin-2 receptor, follicular lymphoma, prognostic factor. patients with asymptomatic disease with a low tumor burden in advanced stage, watchful waiting instead of immediate therapy is often considered appropriate.

Monoclonal antibody combined with chemotherapy is the standard initial therapy for patients with symptomatic FL, for whom various prognostic models have been proposed. The original FL international prognostic index (FLIPI) model and an updated FLIPI2 model were developed in 2004 and 2009, respectively, and have continued to be reliable prognostic models (4). Recently, m7-FLIPI, which includes the mutational status of seven genes as well as the FLIPI factors, was reported to be a better prognostic model (5). However, determination of the precise number of nodal sites involved and mutational analyses are cumbersome and error-prone or difficult to perform, respectively, in routine practice. Moreover, most of the prognostic models have specifically been designed for and applicable to patients with high tumor burden FL requiring immediate therapy.

Therefore, an economical clinical prognostic factor/model applicable to all patients with FL is needed in routine practice. In this regard, beta- 2 microglobulin $(\beta 2-\mathrm{MG})$ has been demonstrated as a useful biomarker at least for patients with FL receiving immediate immunochemotherapy $(6,7)$. Soluble Interleukin-2 receptor (sIL2R) was also reported to be a useful biomarker for FL requiring immediate immunochemotherapy $(8,9)$. However, the prognostic impact of sIL2R, as compared to $\beta 2-\mathrm{MG}$, has not been well elucidated. Thus, in the present study, we retrospectively analyzed the correlation between SIL2R and survival for consecutive patients with FL at diagnosis irrespective of the initial management approach in order to develop a new prognostic model.

\section{Patients and Methods}

Study design and patients. This is a double-institution retrospective analysis of consecutive patients with untreated FL at Tokyo Medical and Dental University Hospital or Yokosuka Kyosai 
Hospital and was performed with approval of each Institutional Review Board (M2018-231).

All patients were diagnosed by biopsy of the primary lesion. Pathological diagnosis was made according to the World Health Organization classification (1). We included grade 1, 2 and 3A FL and excluded grade 3B FL and histological transformation. From consecutive patients, we selected those who had available data on FL grade, bone marrow involvement, serum lactate dehydrogenase (LDH), and sIL2R. Overall, 140 patients with untreated FL diagnosed between July 2007 and January 2018 were included in the study.

Prognostic factors. Medical records of the enrolled cases were reviewed for patient characteristics, disease characteristics, and laboratory data. Clinical characteristics include age, sex, Eastern Cooperative Oncology Group performance status (ECOG PS), and the presence of B symptoms. Disease characteristics include FL grade, Ann Arbor clinical stage, bone marrow involvement, and Groupe d'Etude des Lymphomes Folliculaires (GELF) criteria factors (any site $>7 \mathrm{~cm}$, three or more sites greater than $3 \mathrm{~cm}$, compressive symptoms, pleural or peritoneal effusion, spleen below umbilical line, leukemia). Laboratory data included white blood cell count; absolute lymphocyte count; hemoglobin; platelet count; serum LDH, $\beta 2-\mathrm{MG}$ and sIL2R [upper limit normal (ULN): $519 \mathrm{U} / \mathrm{ml}]$.

Statistical analysis. Event-free survival (EFS) was defined as the time from diagnosis until relapse or progression, unplanned retreatment of lymphoma after initial management, or death due to any cause. EFS24 was defined as the EFS status at 24 months from diagnosis. Progression-free survival (PFS) was defined as the time from the start of initial treatment to the date of disease progression or death. Overall survival (OS) was defined as the time from diagnosis until death from any cause, censoring at the date of last follow-up for patients still alive. The Kaplan-Meier method was used to estimate EFS, PFS and OS. Differences in survival between two groups were analyzed by the log-rank test. Cox proportional hazard regression analysis was performed to evaluate high sIL2R as a prognostic factor for survival as well as to assess and adjust for other known prognostic factors. All reported $p$-values are two-sided, and $p<0.05$ was considered significant. All analyses were carried out using EZR software (Saitama Medical Center, Jichi Medical University, Saitama, Japan), which is a graphical user interface for $\mathrm{R}$ (The $\mathrm{R}$ Foundation for Statistical computing) (10).

\section{Results}

Patient characteristics. Eighty-two and 58 patients were diagnosed at Tokyo Medical and Dental University Hospital and Yokosuka Kyosai Hospital, respectively, with 140 patients in total were analyzed in this study. Patient characteristics are summarized in Table I. The median age of the cohort was 66 (range 34-89) years, and 75\% of patients were categorized as having advanced-stage disease. Fiftythree $(37.9 \%)$ patients presented with bone marrow involvement. While sIL2R was examined in all patients, $\beta 2$ MG was examined in 56 patients $(40 \%)$. The median level of sIL2R was $704.5 \mathrm{U} / \mathrm{ml}$.
Initial management and treatment. Forty-eight patients were initially managed with watchful waiting. Sixteen of these patients $(33.3 \%)$ experienced disease progression (median duration from diagnosis to progression: 15.8 months) and received immunochemotherapy at progression (Tables I and II).

Ninety-two patients were managed with immediate therapies (Table I). Almost all patients who received irradiation had limited-stage disease. All the other patients received rituximab with/without chemotherapy [rituximab, cyclophosphamide, doxorubicin, vincristine and prednisolone (R-CHOP): 43; rituximab, cyclophosphamide, vincristine and prednisolone: 24; rituximab and bendamustine: 6; rituximab monotherapy: 4] (Table II), and only nine patients $(8 \%)$ received rituximab maintenance therapy after initial treatment (Table II).

Event-free survival. At a median follow-up of 51 months (range=4-142 months), the median EFS and the EFS24 rate in the watchful waiting and immediate treatment group were 28 and 33 months, and $67.6 \%$ and $75.6 \%$, respectively. There was no difference between the two groups in EFS (Figure 1A). OS was significantly shorter for patients failing to achieve EFS24 than those achieving it (Figure 1B).

Progression-free survival. Median follow-up after starting initial therapy for patients who received therapy was 47 months (range=0-139 months). PFS was not different between patients receiving initial therapy immediately or after watchful waiting (data not shown).

Prognostic impact of sIL2R. A comparison of characteristics of patients achieving EFS24 or not is summarized in Table III. sIL2R was the only significant factor correlating with EFS24, and the median level of sIL2R at diagnosis in patients achieving EFS24 was significantly lower than those failing to achieve EFS24 (665 and $1208 \mathrm{U} / \mathrm{ml}$, respectively, $p=0.001)$. EFS and OS rates were significantly lower in the group with higher sIL2R (sIL2R >median) (2-year EFS: $66.4 \%$ vs. $87.3 \%, p=0.015$; 5-year OS: $96.0 \%$ vs. $88.9 \%$, $p=0.023$ ), as shown in Figure $2 \mathrm{~A}$ and $\mathrm{B}$. When limited to the immediate treatment group, similar results were obtained, although the difference in EFS did not reach the significant level (Figure 2C and D). Next, we investigated the prognostic impact of the degree of increase in sIL2R level. Patients were categorized into three groups according to sIL2R level at diagnosis: low, $\leq \mathrm{ULN}, \mathrm{n}=51$; high, ULN to $\leq 5 \times \mathrm{ULN}, \mathrm{n}=62$; very high, $>5 \times \mathrm{ULN}, \mathrm{n}=27)$. EFS and OS were plotted according to the sIL2R level (Figure 3A, B). Although there was no survival difference between the groups with low and high sIL2R level when limited to patients who received immediate treatment, the group with a very high sIL2R level showed significantly poorer survival (Figure 3C and D). 
Table I. Patient characteristics.

\begin{tabular}{|c|c|}
\hline Characteristic & $\mathrm{N}=140$ \\
\hline \multicolumn{2}{|l|}{ Age, years } \\
\hline Median (range) & $66(34-89)$ \\
\hline \multicolumn{2}{|l|}{ Gender, n (\%) } \\
\hline Male & $65(46.4 \%)$ \\
\hline \multicolumn{2}{|c|}{ Follicular lymphoma grade, n (\%) } \\
\hline 1 & $47(33.6 \%)$ \\
\hline 2 & $55(39.3 \%)$ \\
\hline $3 \mathrm{a}$ & $38(27.1 \%)$ \\
\hline \multicolumn{2}{|l|}{ Clinical stage, $\mathrm{n}(\%)$} \\
\hline 1 & $13(9.3 \%)$ \\
\hline 2 & $22(15.7 \%)$ \\
\hline 3 & $35(25.0 \%)$ \\
\hline 4 & $70(50 \%)$ \\
\hline \multicolumn{2}{|c|}{ Bone marrow involvement, $\mathrm{n}(\%)$} \\
\hline Yes & $53(37.9 \%)$ \\
\hline \multicolumn{2}{|l|}{ B Symptoms, n (\%) } \\
\hline Yes & $5(3.6 \%)$ \\
\hline \multicolumn{2}{|l|}{ Any site $>7 \mathrm{~cm}, \mathrm{n}(\%)$} \\
\hline Yes & $28(20 \%)$ \\
\hline \multicolumn{2}{|c|}{ Three or more sites $>3 \mathrm{~cm}, \mathrm{n}(\%)$} \\
\hline Yes & $18(12.9 \%)$ \\
\hline \multicolumn{2}{|c|}{ Compression symptoms, n (\%) } \\
\hline Yes & $21(15 \%)$ \\
\hline \multicolumn{2}{|c|}{ Pleural or peritoneal effusion, $\mathrm{n}(\%)$} \\
\hline Yes & $12(8.6 \%)$ \\
\hline \multicolumn{2}{|c|}{ Spleen below umbilical line, n (\%) } \\
\hline Yes & $8(5.7 \%)$ \\
\hline \multicolumn{2}{|l|}{ Leukemia, n (\%)* } \\
\hline Yes & $1(0.7 \%)$ \\
\hline \multicolumn{2}{|l|}{ White blood count, $\mathrm{n} / \mu \mathrm{l}$} \\
\hline Median (range) & $5,500(3,000-25,200)$ \\
\hline \multicolumn{2}{|c|}{ Absolute lymphocyte count, $\mathrm{n} / \mu \mathrm{l}$} \\
\hline Median (range) & $1,302(400-16,128)$ \\
\hline \multicolumn{2}{|l|}{ Hemoglobin, g/dl } \\
\hline Median (range) & $13.45(7.0-17.5)$ \\
\hline \multicolumn{2}{|l|}{ Platelet count, $n \times 10^{4} / u l$} \\
\hline Median (range) & $21.85(6.2-63.7)$ \\
\hline \multicolumn{2}{|l|}{$\mathrm{LDH}, \mathrm{U} / \mathrm{l}$} \\
\hline Median (range) & $194.5(116-1,411)$ \\
\hline \multicolumn{2}{|l|}{$\beta-2$ Microglobulin, $\mathrm{mg} / \mathrm{dl}$} \\
\hline Median (range) & $1.8(0.82-11.92)$ \\
\hline Missing data & $84(60 \%)$ \\
\hline \multicolumn{2}{|l|}{$\mathrm{sIL} 2 \mathrm{R}, \mathrm{U} / \mathrm{ml}$} \\
\hline Median (range) & $704.5(159-15,500)$ \\
\hline \multicolumn{2}{|l|}{ Initial plan, n (\%) } \\
\hline Watchful waiting & $48(34.3 \%)$ \\
\hline Immediate treatment & $92(65.7 \%)$ \\
\hline
\end{tabular}

LDH: Lactate dehydrate; sIL2R: soluble interleukin-2 receptor. *Tumor cells $>51,000 / \mu \mathrm{l}$ in peripheral blood.

Univariate and multivariate analyses of survival. Cox proportional hazard regression analysis was performed to evaluate very high sIL2R level as a prognostic factor for EFS and OS, as well as to assess and adjust for other known prognostic factors. Variables analyzed were age, Ann Arbor
Table II. Treatment of study patients.

\begin{tabular}{lcr}
\hline & Treatment & N \\
\hline Immediate (N=92) & Radiation & 15 \\
& R monotherapy & 4 \\
R-CHOP & 43 \\
& R-CVP & 24 \\
& R-Bendamustine & 6 \\
R Maintenance & 8 \\
After watchful waiting (N=16) & Radiation & 0 \\
& R Monotherapy & 1 \\
& R-CHOP & 5 \\
& R-CVP & 8 \\
& R-Bendamustine & 2 \\
R Maintenance & 1 \\
\hline
\end{tabular}

R: Rituximab; CHOP: cyclophosphamide, doxorubicin, vincristine and prednisolone; CVP: cyclophosphamide, vincristine and prednisolone.

clinical stage, bone marrow involvement, B symptom, GELF criteria factors, $\mathrm{LDH}$, and sIL2R. The leukemia factor of GELF criteria was excluded because only one patient showed leukemic disease (Table IV). From the univariate analysis, a very high sIL2R level and clinical stage or age were selected for the multivariate analysis for EFS and OS, respectively. As shown in Table IV, a very high sIL2R level was the only independent prognostic factor for both EFS and OS.

\section{Discussion}

It is difficult to predict OS of patients with FL at diagnosis because of various initial management approaches available as well as the incurable and prolonged indolent clinical course. Based on data from patients who received immediate immunochemotherapy, recent studies reported that early progression after immunochemotherapy predicts poorer OS (11-13). A more recent study demonstrated that early events as defined by EFS12 predicted OS of all patients newly diagnosed with FL including those observed initially, without treatment, although the impact of EFS12 seemed to be especially important for patients requiring immunochemotherapy immediately (14). The present study has confirmed that early events after diagnosis predict poor outcomes in patients newly diagnosed with FL overall, although EFS24 seemed to have a more powerful impact on survival than EFS12 in our cohort of patients (data not shown).

Of various factors we analyzed in the present study, sIL2R was the only one to show a significant correlation with EFS24, which proved to be a strong prognostic parameter for subsequent OS (Table III). Thus, a higher than median sIL2R level led to lower rates not only for 2-year EFS but also for 5-year OS than did lower sIL2R levels (Figure 2). Previous studies have shown that a high sIL2R level in patients with 

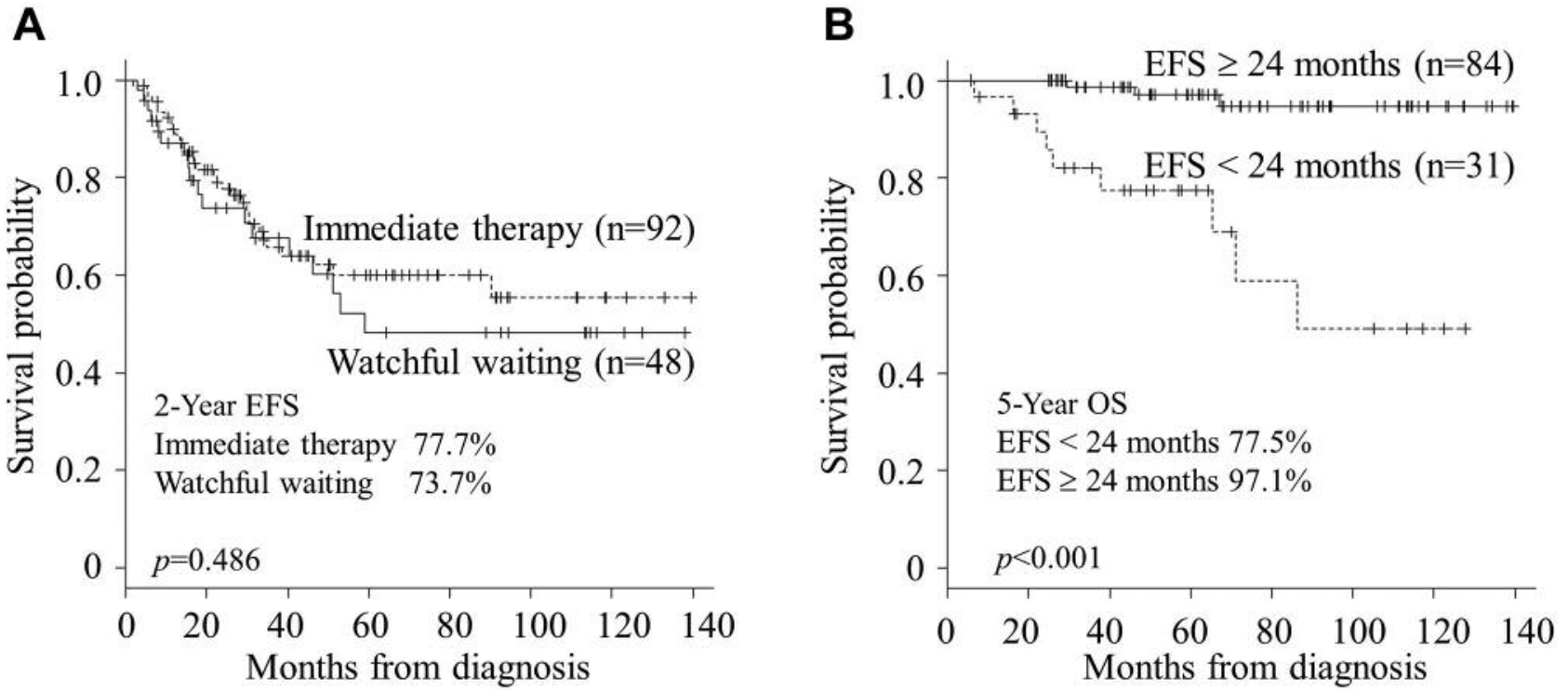

Figure 1. A: Event-free survival (EFS) according to initial management approaches. B: Overall survival (OS) according to EFS at 24 months (EFS24).

Table III. Patient characteristics according to achievement of event-free survival (EFS24).

\begin{tabular}{|c|c|c|c|c|}
\hline \multirow[b]{2}{*}{ Characteristic } & & \multicolumn{2}{|c|}{ EFS } & \multirow[b]{2}{*}{$p$-Value } \\
\hline & & $\geq 24$ Months $(\mathrm{n}=84)$ & $<24$ Months $(\mathrm{n}=31)$ & \\
\hline Age, years & Median (range) & $64(33-89)$ & $65(51-80)$ & 0.621 \\
\hline Gender, n $(\%)$ & Male & $39(46.4 \%)$ & $16(51.6 \%)$ & 0.677 \\
\hline Clinical stage, n (\%) & Advanced* & $62(73.8 \%)$ & $27(87.1 \%)$ & 0.208 \\
\hline Bone marrow involvement, $\mathrm{n}(\%)$ & Yes & $34(40.5 \%)$ & $12(38.7 \%)$ & $>0.99$ \\
\hline B Symptoms, n (\%) & Yes & $3(3.6 \%)$ & $1(3.2 \%)$ & $>0.99$ \\
\hline \multirow[t]{3}{*}{ Follicular lymphoma grade, n (\%) } & 1 & $30(35.7 \%)$ & $12(38.7 \%)$ & 0.895 \\
\hline & 2 & $34(40.5 \%)$ & $11(35.5 \%)$ & \\
\hline & $3 a$ & $20(23.8 \%)$ & $8(25.8 \%)$ & \\
\hline Any site $>7 \mathrm{~cm}, \mathrm{n}(\%)$ & Yes & $15(17.9 \%)$ & $9(29.0 \%)$ & 0.204 \\
\hline Three or more sites $>3 \mathrm{~cm}, \mathrm{n}(\%)$ & Yes & $10(12.0 \%)$ & $4(12.9 \%)$ & $>0.99$ \\
\hline Compression symptoms, n (\%) & Yes & $11(13.1 \%)$ & $8(25.8 \%)$ & 0.154 \\
\hline Pleural or peritoneal effusion, $\mathrm{n}(\%)$ & Yes & $7(8.3 \%)$ & $4(12.9 \%)$ & 0.484 \\
\hline \multirow[t]{2}{*}{ Initial plan, $\mathrm{n}(\%)$} & Watchful waiting & $25(29.8 \%)$ & $12(38.7 \%)$ & 0.376 \\
\hline & Immediate treatment & $59(70.2 \%)$ & $19(61.3 \%)$ & \\
\hline White blood count, $\mathrm{n} / \mu \mathrm{l}$ & Median (range) & $5,550(3,000-25,200)$ & $5,500(3,600-21,500)$ & 0.412 \\
\hline Absolute lymphocyte count, $\mathrm{n} / \mu \mathrm{l}$ & Median (range) & $1,324(400-16,128)$ & $1,302(430-2,613)$ & 0.962 \\
\hline Hemoglobin, g/dl & Median (range) & $13.5(7.7-17.2)$ & $13.2(7.0-17.5)$ & 0.451 \\
\hline Platelet count, $\mathrm{n} \times 104 / \mu \mathrm{l}$ & Median (range) & $20.7(6.2-40.8)$ & $23.1(15.7-63.7)$ & 0.105 \\
\hline $\mathrm{LDH}, \mathrm{U} / 1$ & Median (range) & $190(116-407)$ & $198(116-1411)$ & 0.086 \\
\hline sIL2R, U/ml & Median (range) & $644(159-7,640)$ & $1,208(208-15,500)$ & 0.001 \\
\hline
\end{tabular}

LDH: Lactate dehydrate; sIL2R: soluble interleukin-2 receptor. *Clinical stage 3 or 4.

FL was also associated significantly with PFS but only marginally with OS, which may be because those studies were limited to patients achieving complete/partial remission after immunochemotherapy or to a small number of only 70 patients $(8,9)$. Therefore, the present study has not only confirmed but also extended the findings of these previous studies by demonstrating that a high sIL2R level in patients newly diagnosed with FL correlates significantly with poor 

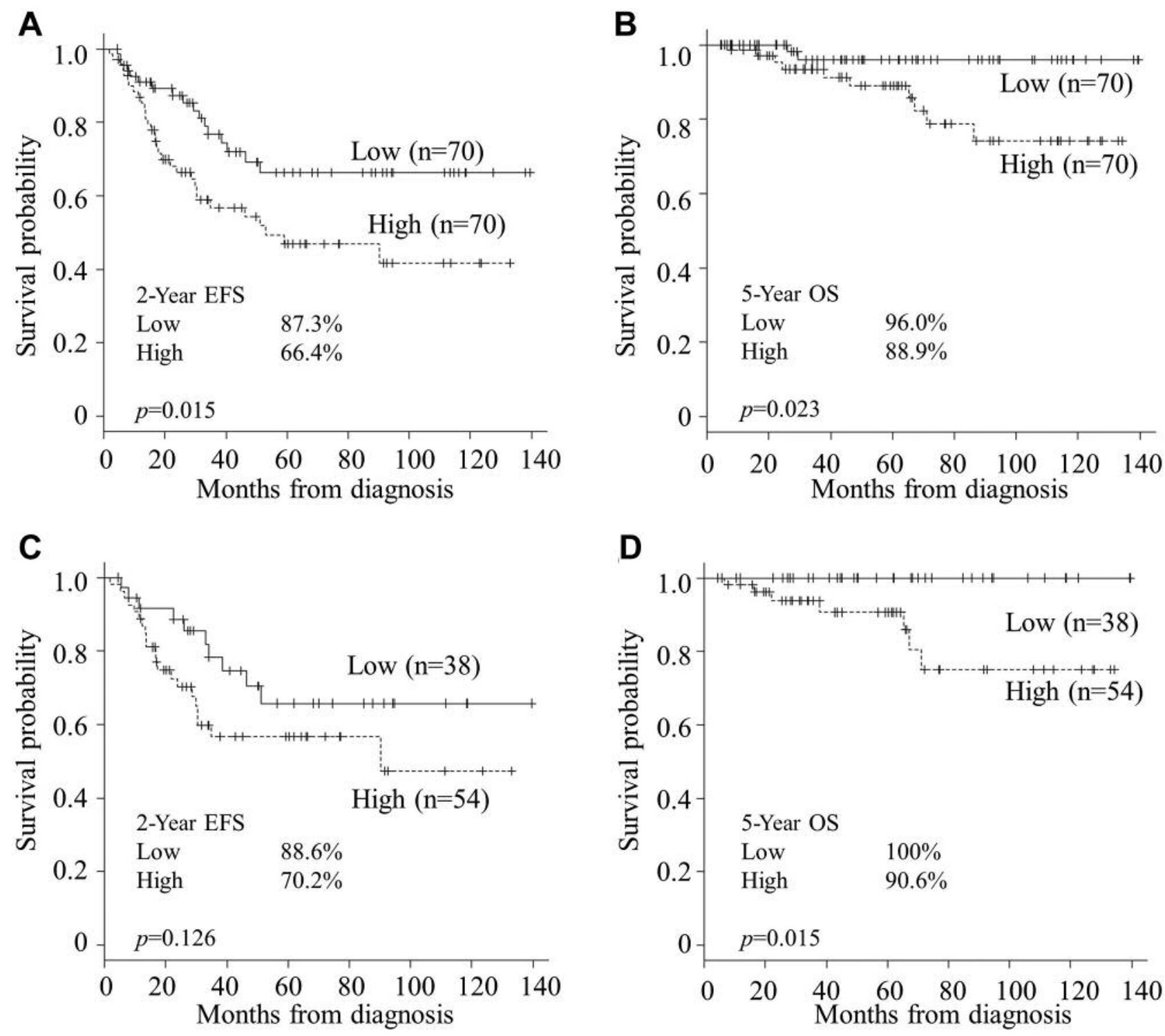

Figure 2. Event-free survival (EFS) and overall survival (OS) according to the level of soluble interleukin-2 receptor (sIL2R) using the median as a cutoff considering all patients ( $A$ and $B$, respectively) and patients treated immediately ( $C$ and $D$, respectively).

OS as well as EFS, irrespective of initial management approach. Furthermore, when categorized into three groups, a very high level of sIL2R was identified as the only significant predictor of OS as well as EFS in univariate and multivariate analyses (Table IV). Importantly, the group with a very high sIL2R level, consisting of about $20 \%$ of patients with most requiring immediate therapy, had a distinctively poor prognosis with 2-year EFS and 5-year OS of around $50 \%$ and $90 \%$, respectively (Figure 3 ).

Recently, a new simple prognostic index for FL, PRIMAPI, comprising only two simple parameters ( $\beta 2-\mathrm{MG}$ and bone marrow involvement) has been proposed to predict PFS and OS (7). However, this tool was built based solely on a cohort of patients treated with initial immunochemotherapy and is not applicable to all patients newly diagnosed with FL. Moreover, with the broader use of positron-emission tomography/computed tomography in the clinical staging assessment of FL, bone marrow biopsy may not be most convenient, especially for patients not requiring immediate immunotherapy in routine practice, as indicated by others (7). $\beta 2-\mathrm{MG}$ has also been combined with $\mathrm{LDH}$ to provide a simple prognostic index for patients with FL treated immediately with R-CHOP or CHOP followed by radioimmunotherapy (6). Similarly to our model with sIL2- 
A
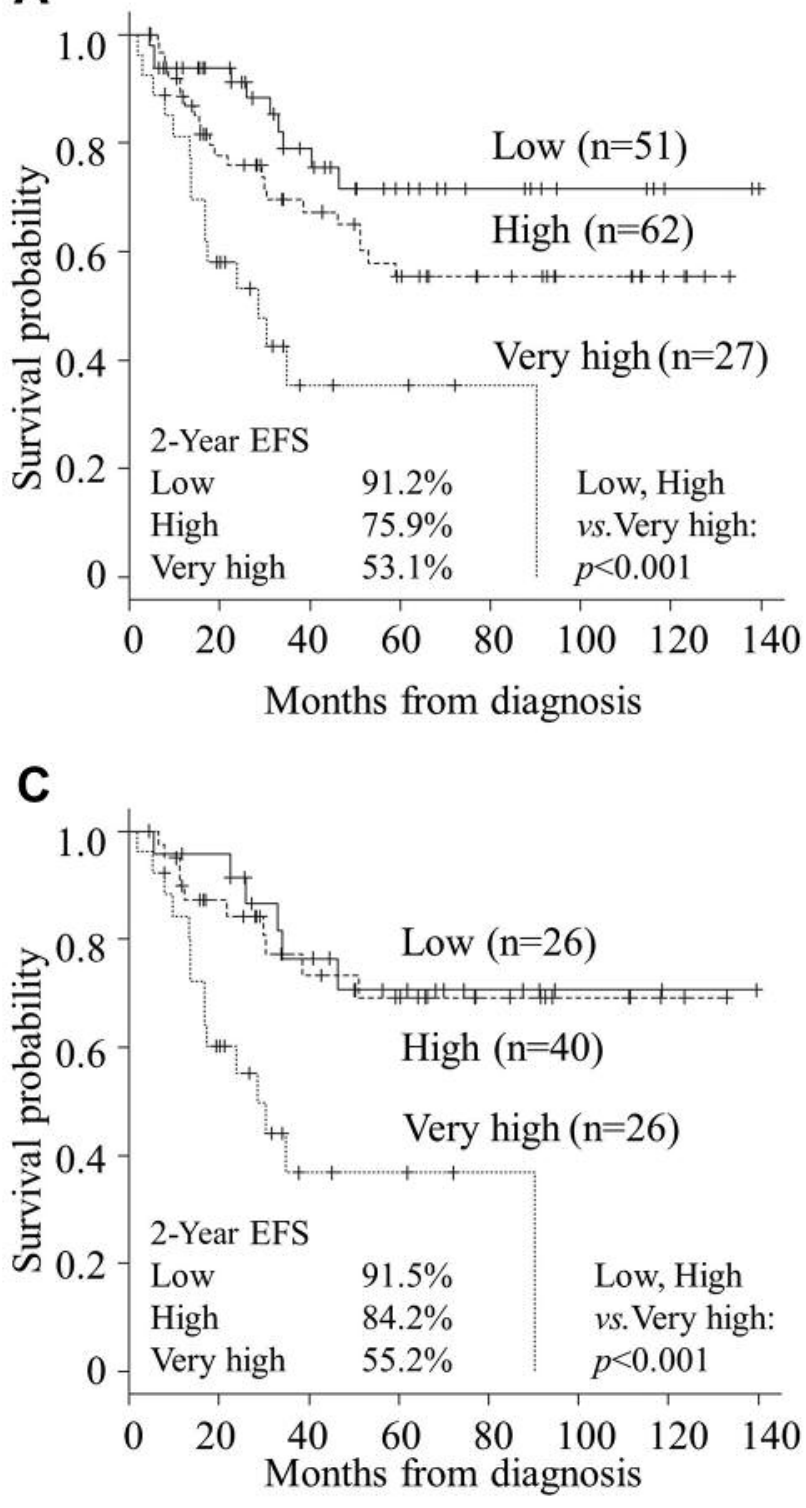

B

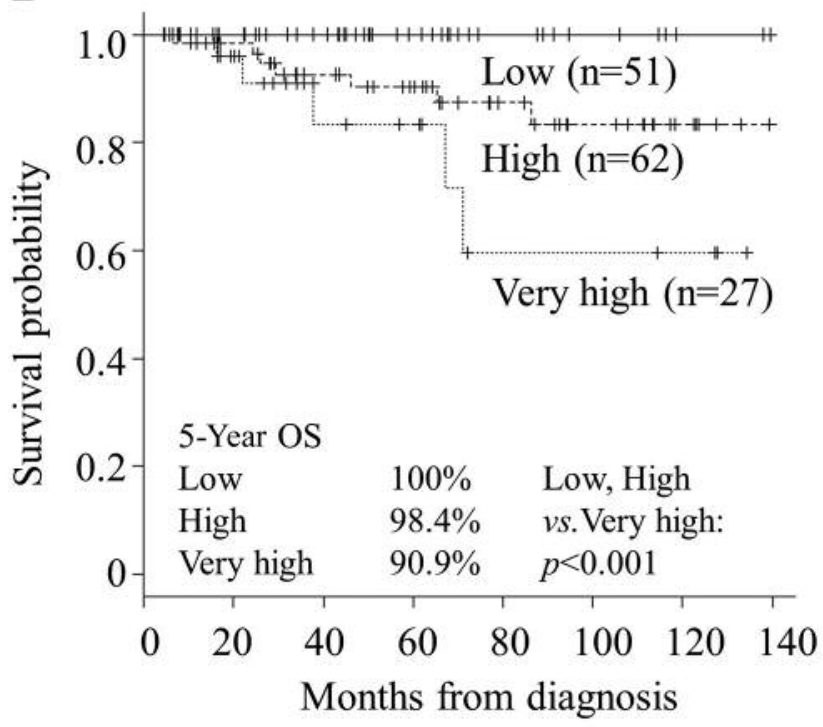

D

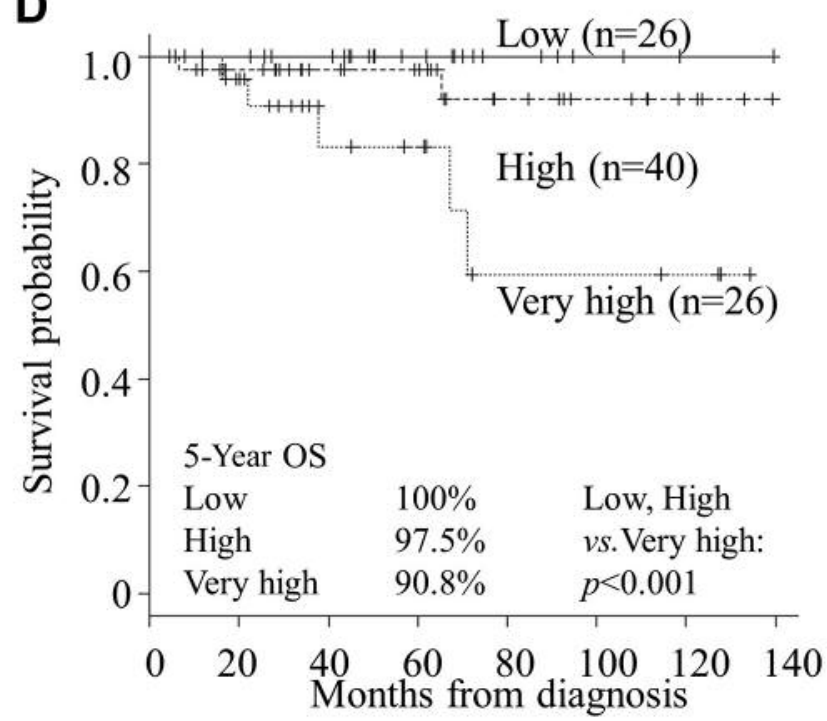

Figure 3. Event-free survival (EFS) and overall survival (OS) according to soluble interleukin-2 receptor (sIL2R) level considering all patients (A and $B$, respectively) and patients treated immediately ( $C$ and $D$, respectively). Patients were categorized into three groups according to sIL2R level at diagnosis: Low: Less than the upper limit of normal (ULN), $n=51 ;$ high: ULN to $\leq 5 \times U L N, n=62 ;$ very high: $>5 \times U L N, n=27)$.

$\mathrm{R}$, an increase of the cutoff for $\beta 2-\mathrm{MG}$ enabled identification of about $20 \%$ of patients destined for early relapse and poor OS among patients with FL with high-burden disease requiring immediate treatment with immunochemotherapy. As compared with these models using $\beta 2-\mathrm{MG}$, our model is more economical and can be used very easily in routine practice for all patients newly diagnosed with FL to predict OS as well as early progression.

The major limitation of the present study, however, is that it was a retrospective study of a relatively limited number of patients. Therefore, future large prospective studies are warranted to validate the present model and to verify its ability to identify early on the small group of patients with very poor risk, which merits consideration of novel upfront therapeutics, such as obinutuzumab instead of rituximab (15) in order to reduce the early progression rate.

\section{Conflicts of Interest}

The Authors declare no conflict of interest in regard to this study 
Table IV. Univariate and multivariate analyses for event-free survival (EFS) and overall survival (OS).

\begin{tabular}{|c|c|c|c|c|c|c|c|c|c|c|c|c|}
\hline \multirow[b]{3}{*}{ Factor } & \multicolumn{6}{|c|}{ EFS } & \multicolumn{6}{|c|}{ OS } \\
\hline & \multicolumn{3}{|c|}{ Univariate analysis } & \multicolumn{3}{|c|}{ Multivariate analysis } & \multicolumn{3}{|c|}{ Univariate analysis } & \multicolumn{3}{|c|}{ Multivariate analysis } \\
\hline & HR & $95 \% \mathrm{CI}$ & $p$-Value & HR & $95 \% \mathrm{CI}$ & $p$-Value & HR & $95 \% \mathrm{CI}$ & $p$-Value & HR & $95 \% \mathrm{CI}$ & $p$-Value \\
\hline \multicolumn{13}{|l|}{ sIL2R } \\
\hline$>5 \times \mathrm{ULN}$ & 3 & $1.63-5.51$ & $<0.001$ & 2.68 & $1.43-5.01$ & 0.002 & 3.94 & $1.24-12.48$ & 0.02 & 3.88 & $1.22-12.35$ & 0.022 \\
\hline \multicolumn{13}{|l|}{ Clinical stage } \\
\hline Advanced* & 2.09 & $0.94-4.66$ & 0.07 & 1.66 & $0.72-3.78$ & 0.232 & 1.63 & $0.36-7.46$ & 0.527 & & & \\
\hline \multicolumn{13}{|l|}{ Age } \\
\hline$>70$ Years & 0.74 & $0.38-1.45$ & 0.386 & & & & 3.02 & $0.97-9.392$ & 0.056 & 2.97 & $0.95-9.27$ & 0.061 \\
\hline \multicolumn{13}{|l|}{ B Symptoms } \\
\hline Yes & 0.53 & $0.07-3.87$ & 0.534 & & & & 4.01 & $0.5-32.25$ & 0.191 & & & \\
\hline \multicolumn{13}{|c|}{ Bone marrow involvement } \\
\hline Yes & 1.33 & $0.76-2.35$ & 0.317 & & & & 1.76 & $0.56-5.48$ & 0.33 & & & \\
\hline \multicolumn{13}{|c|}{ Pleural or peritoneal effusion } \\
\hline Yes & 0.89 & $0.32-2.48$ & 0.822 & & & & 0.98 & $0.13-7.61$ & 0.987 & & & \\
\hline \multicolumn{13}{|c|}{ Three or more sites $>3 \mathrm{~cm}$} \\
\hline Yes & 1.17 & $0.53-2.61$ & 0.698 & & & & - & 0-Inf & 0.998 & & & \\
\hline \multicolumn{13}{|c|}{ Compression symptoms } \\
\hline Yes & 1.45 & $0.7-2.99$ & 0.32 & & & & 2.13 & $0.57-7.91$ & 0.258 & & & \\
\hline \multicolumn{13}{|c|}{ Any site $>7 \mathrm{~cm}$} \\
\hline Yes & 1.24 & $0.63-2.43$ & 0.53 & & & & 0.98 & $0.2-4.31$ & 0.934 & & & \\
\hline \multicolumn{13}{|l|}{$\mathrm{LDH}$} \\
\hline$>\mathrm{ULN}$ & 1.34 & $0.72-2.49$ & 0.359 & & & & 1.14 & $0.31-4.2$ & 0.85 & & & \\
\hline
\end{tabular}

CI: Confidence intervaI; HR: hazard ratio; LDH: lactate dehydrate; sIL2R: soluble interleukin-2 receptor; ULN: upper limit of normal. *Clinical stage 3 or 4 .

\section{Authors' Contributions}

Masahide Yamamoto: Study design, data collection, analysis and interpretation of results, statistical analyses, construction of figures, editing and writing of article; Keisuke Tanaka: data collection and patient management; Yoshihiro Umezawa: data collection and patient management; Toshikage Nagao: data collection and patient management; Shigeo Toyota: data collection and patient management; Osamu Miura: supervision of the project, critical revision of the article. All the Authors read and approved the final article.

\section{References}

1 Swerdlow SH, Campo E, Harris NL, Jaffe ES, Pileri SA, Stein H, Thiele J, Arber DA, Hasserjian RP, Le Beau MM, Orazi A and Siebert R: WHO Classification of Tumours of Haematopoietic and Lymphoid Tissues. Revised Fourth Edition. Lyon: IARC, 2017.

2 Muto R, Miyoshi H, Sato K, Furuta T, Muta H, Kawamoto K, Yanagida E, Yamada $\mathrm{K}$ and Ohshima K: Epidemiology and secular trends of malignant lymphoma in Japan: Analysis of 9426 cases according to the World Health Organization classification. Cancer Med 7(11): 5843-5858, 2018. PMID: 30311404. DOI: 10.1002/cam4.1805

3 Tan D, Horning SJ, Hoppe RT, Levy R, Rosenberg SA, Sigal BM, Warnke RA, Natkunam Y, Han SS, Yuen A, Plevritis SK and Advani RH: Improvements in observed and relative survival in follicular grade 1-2 lymphoma during 4 decades: The Stanford University experience. Blood 122(6): 981-987, 2013. PMID: 23777769. DOI: 10.1182/blood-2013-03-491514

4 Federico M, Bellei M, Marcheselli L, Luminari S, LopezGuillermo A, Vitolo U, Pro B, Pileri S, Pulsoni A, Soubeyran P, Cortelazzo S, Martinelli G, Martelli M, Rigacci L, Arcaini L, Di Raimondo F, Merli F, Sabattini E, McLaughlin P and SolalCéligny P: Follicular Lymphoma International Prognostic Index 2: A new prognostic index for follicular lymphoma developed by the International Follicular Lymphoma Prognostic Factor project. J Clin Oncol 27(27): 4555-4562, 2009. PMID: 19652063. DOI: $10.1200 / J C O .2008 .21 .3991$

5 Pastore A, Jurinovic V, Kridel R, Hoster E, Staiger AM, Szczepanowski M, Pott C, Kopp N, Murakami M, Horn H, Leich E, Moccia AA, Mottok A, Sunkavalli A, Van Hummelen P, Ducar M, Ennishi D, Shulha HP, Hother C, Connors JM, Sehn LH, Dreyling M, Neuberg D, Möller P, Feller AC, Hansmann ML, Stein H, Rosenwald A, Ott G, Klapper W, Unterhalt M, Hiddemann W, Gascoyne RD, Weinstock DM and Weigert O: Integration of gene mutations in risk prognostication for patients receiving first-line immunochemotherapy for follicular lymphoma: A retrospective analysis of a prospective clinical trial and validation in a populationbased registry. Lancet Oncol 16(9): 1111-1122, 2015. PMID: 26256760. DOI: 10.1016/S1470-2045(15)00169-2

6 Press OW, Unger JM, Rimsza LM, Friedberg JW, LeBlanc M, Czuczman MS, Kaminski M, Braziel RM, Spier C, Gopal AK, Maloney DG, Cheson BD, Dakhil SR, Miller TP and Fisher RI: 
A comparative analysis of prognostic factor models for follicular lymphoma based on a phase III trial of CHOP-rituximab versus CHOP + 131iodine-tositumomab. Clin Cancer Res 19(23): 6624-6632, 2013. PMID: 24130072. DOI: 10.1158/10780432.CCR-13-1120

7 Bachy E, Maurer MJ, Habermann TM, Gelas-Dore B, MaucortBoulch D, Estell JA, Van den Neste E, Bouabdallah R, Gyan E, Feldman AL, Bargay J, Delmer A, Slager SL, Gomes da Silva M, Fitoussi O, Belada D, Maisonneuve H, Intragumtornchai T, Ansell SM, Lamy T, Dartigues P, Link BK, Seymour JF, Cerhan JR and Salles G: A simplified scoring system in de novo follicular lymphoma treated initially with immunochemotherapy. Blood 132(1): 49-58, 2018. PMID: 29666118. DOI: 10.1182/ blood-2017-11-816405

8 Yoshizato T, Nannya Y, Imai Y, Ichikawa M and Kurokawa M: Clinical significance of serum-soluble interleukin-2 receptor in patients with follicular lymphoma. Clin Lymphoma Myeloma Leuk 13(4): 410-416, 2013. PMID: 23747081. DOI: 10.1016/j.clml.2013.03.014

9 Kusano Y, Yokoyama M, Terui Y, Inoue N, Takahashi A, Yamauchi H, Tsuyama N, Nishimura N, Mishima Y, Takeuchi K and Hatake K: High pretreatment level of soluble interleukin-2 receptor is a robust prognostic factor in patients with follicular lymphoma treated with R-CHOP-like therapy. Blood Cancer J 7(9): e614, 2017. PMID: 28960192. DOI: 10.1038/bcj.2017.96

10 Kanda Y: Investigation of the freely available easy-to-use software 'EZR' for medical statistics. Bone Marrow Transplant 48(3): 452-458, 2013. PMID: 23208313. DOI: 10.1038/bmt. 2012.244

11 Casulo C, Byrtek M, Dawson KL, Zhou X, Farber CM, Flowers CR, Hainsworth JD, Maurer MJ, Cerhan JR, Link BK, Zelenetz $\mathrm{AD}$ and Friedberg JW: Early relapse of follicular lymphoma after rituximab plus cyclophosphamide, doxorubicin, vincristine, and prednisone defines patients at high risk for death: An analysis from the National Lymphocare Study. J Clin Oncol 33(23): 2516-2522, 2015. PMID: 26124482. DOI: 10.1200/ JCO.2014.59.7534
12 Jurinovic V, Kridel R, Staiger AM, Szczepanowski M, Horn H, Dreyling MH, Rosenwald A, Ott G, Klapper W, Zelenetz AD, Barr PM, Friedberg JW, Ansell S, Sehn LH, Connors JM, Gascoyne RD, Hiddemann W, Unterhalt M, Weinstock DM and Weigert O: Clinicogenetic risk models predict early progression of follicular lymphoma after first-line immunochemotherapy. Blood 128(8): 1112-1120, 2016. PMID: 27418643. DOI: 10.1182/blood-2016-05-717355

13 Lansigan F, Barak I, Pitcher B, Jung SH, Cheson BD, Czuczman M, Martin P, Hsi E, Schöder H, Smith S, Bartlett NL, Leonard JP and Blum KA: The prognostic significance of PFS24 in follicular lymphoma following first-line immunotherapy: A combined analysis of 3 CALGB trials. Cancer Med 8(1): 165173, 2019. PMID: 30575311. DOI: 10.1002/cam4.1918

14 Maurer MJ, Bachy E, Ghesquières H, Ansell SM, Nowakowski GS, Thompson CA, Inwards DJ, Allmer C, Chassagne-Clément C, Nicolas-Virelizier E, Sebban C, Lebras L, Sarkozy C, Macon WR, Feldman AL, Syrbu SI, Traverse-Glehan A, Coiffier B, Slager SL, Weiner GJ, Witzig TE, Habermann TM, Salles G, Cerhan JR and Link BK: Early event status informs subsequent outcome in newly diagnosed follicular lymphoma. Am J Hematol 91(11): 1096-1101, 2016. PMID: 27465588. DOI: 10.1002/ajh.24492

15 Seymour JF, Marcus R, Davies A, Gallop-Evans E, Grigg A, Haynes A, Herold M, Illmer T, Nilsson-Ehle H, Sökler M, Dünzinger $\mathrm{U}$, Nielsen $\mathrm{T}$, Launonen $\mathrm{A}$ and Hiddemann $\mathrm{W}$ : Association of early disease progression and very poor survival in the gallium study in follicular lymphoma: Benefit of obinutuzumab in reducing the rate of early progression. Haematologica 104(6): 1202-1208, 2019. PMID: 30573503. DOI: $10.3324 /$ haematol.2018.209015

Received July 13, 2019

Revised August 4, 2019

Accepted August 7, 2019 